\title{
CHLORIDE RESISTANCE OF NANO-PARTICLE REPAIRED CONCRETE
}

\author{
Rostislav Šulc*, Michal Himmel, JiŘí NĚmeČEK \\ Czech Technical University in Prague, Faculty of Civil Engineering, Department of Construction Technology, \\ Thákurova 7/207r, 16629 Prague 6, Czech Republic \\ * corresponding author: rostislav.sulc@fsv.cvut.cz
}

\begin{abstract}
This paper describes the results of the experimentally modeled chloride ion penetration into different quality concrete structures with fully developed carbonation. Parts of concrete samples were further treated, to increase the resistance of concrete to chloride ion penetration, with a colloidal solution of Nano-silica or solution of Sodium Methyl Siliconate. Measurement of chloride profiles was performed on samples subjected to free diffusion of $\mathrm{Cl}^{-}$ions and on samples subjected to accelerated tests. The chloride ion profile in the samples was determined in layers of $5 \mathrm{~mm}$ thickness up to a total of $45 \mathrm{~mm}$. [1, 2]
\end{abstract}

KEYwords: Chloride resistance, nano-particle, nano-silica, concrete resistance, chloride accelerated test, natural diffusion.

\section{INTRODUCTION}

The motivation for this experiment is to verify the possibilities of using nano-sized particles to close the porous structure of the concrete. Therefore, a colloidal solution nano-silica (NS) or $10 \%$ solution of Sodium Methyl Siliconate (SMS) were used for post-mix treatment of concrete. The solid particles of the solution fill up and clog the open pores that are entering points for salt molecules into the concrete. Such a closed structure should better withstand aggressive salt water and thereby increase the resistance of concrete to counteract the action of chlorides dissolved in water. The result of this experiment is to provide information on the amount of chlorides penetrating into the depth of the concrete and to limit the possibility of reducing the amount of chlorides entering the concrete structure by closing the microstructure of the concrete. For this test were the used mixtures of concrete also fully carbonated. [1] 4

\section{Materials AND MiX PROPORTIONS}

Concrete specimens were made from Portland cement (CEM I 42.5 R location Mokrá) as a binder and sand and natural crushed aggregate from Zbraslav location were used as aggregate. No other admixtures or additives were used. In Table 1 is shown mixture composition per $1 \mathrm{~m}^{3}$. For this experiment was prepared mixture so called "Normal concrete" (NO2a) quality concrete with predicated compressive strength over $40 \mathrm{MPa}$. Second was used so called "low quality concrete" with compressive strength around $20 \mathrm{MPa}$. Concrete was mixed for 5 minutes in laboratory concrete mixer, subsequently was mixture cast into cylindrical and cubic moulds and vibrated. The samples were unmoulded and submerged into water bath after 48 hours for mixing. Testing cubes of dimensions
$150 \times 150 \times 150 \mathrm{~mm}$ were used for compressive strength test and from cylinders with $100 \mathrm{~mm}$ in diameter and height of $200 \mathrm{~mm}$ were prepared test samples with a diameter of $100 \mathrm{~mm}$ and a height of $50 \mathrm{~mm}$ for the chloride migration tests.

Measured compressive strength of testing concrete samples was $48.9 \mathrm{MPa}$ for concrete NO2a. This value was determined as the average of three test specimens. The average bulk density of the concrete was $2351 \mathrm{~kg} \cdot \mathrm{m}^{-3}$. This value was also determined as the average of three test specimens. For concrete LO2 these numbers are: $20.5 \mathrm{MPa}$ and $2230 \mathrm{~kg} \cdot \mathrm{m}^{-3}$.

After cutting of samples was done, the carbonation process began. Samples were left in storage box with moisture around $65 \%$ and slow income of gas carbon dioxide $\mathrm{CO}_{2}$. Until the phenolphthalein test indicated that the samples were fully carbonated.

\section{USED METHODS}

\subsection{VACUUM PENETRATION}

All samples were stored in desiccator in vacuum for minimum of 2 hours. After this was done, distilled water was poured in, so the samples were fully submerged, and after than vacuum was done again in desiccator. Thus, the samples were penetrated with water in vacuum for another minimum of 2 hours. 4

\subsection{NATURAL CHLORIDE PENETRATION}

The samples were coated on the underside and the sides with the epoxy adhesive. Than the samples were placed in the mold base for the test of natural diffusion. Subsequently, vacuum penetration as described above, was performed on the samples. Next, a collar was enclosed in the mold and the samples were sealed from all sides except the upper surface. Then the samples were submerged in $3 \% \mathrm{NaCl}$ solution and, 


\begin{tabular}{llccccc}
\hline & \multicolumn{2}{c}{ Binder } & \multicolumn{3}{c}{ Aggregate } & \multirow{2}{*}{ Water ratio } \\
\cline { 3 - 5 } & & CEM I-42.5R & $0-4 \mathrm{~mm}$ & $4-8 \mathrm{~mm}$ & $8-16 \mathrm{~mm}$ & water/binder \\
\hline \multirow{2}{*}{$\left(\mathrm{kg} / \mathrm{m}^{3}\right)$} & NO2a & 436.4 & 872.7 & 581.8 & 290.9 & 186.0 \\
& LO2 & 261.8 & 1150 & 581.8 & 291 & 210.2 \\
\hline
\end{tabular}

TABle 1. Definition of concrete composition.

\begin{tabular}{lc}
\hline Silica [wt.\%] & 50 \\
$\mathrm{pH}$ & 9.5 \\
Viscosity $[\mathrm{cP}]$ & 8 \\
Density $\left[\mathrm{g} \cdot \mathrm{cm}^{-3}\right]$ & 1.4 \\
\hline
\end{tabular}

TABle 2. Typical properties of Levasil CB8 [5].

\begin{tabular}{ll}
\hline CAS No. & $16589-43-8$ \\
EINECS No. & $240-648-3$ \\
Formula & $\mathrm{CH}_{6} \mathrm{O}_{3} \mathrm{Si} \cdot \mathrm{xNa}$ \\
Flash point & $>100{ }^{\circ} \mathrm{C}$ \\
Color and appearance & colorless clear liquid \\
Solid contents & $30 \%$ \\
Silicone solids contents & $19 \%$ \\
pH value & $12-13$ \\
Density $25 / 25^{\circ} \mathrm{C}$ & 1.25 \\
\hline
\end{tabular}

TABlE 3. Typical properties of Sodium Methyl Siliconate.

top of mold was sealed to eliminate evaporation, and kept in constant laboratory temperature $\left(22 \pm 2{ }^{\circ} \mathrm{C}\right)$ for approximately 150 days. After these workflows were done, the samples were dried in heat chamber at $55^{\circ} \mathrm{C}$ for at least 7 days.

\subsection{Protection By Dispersion of COLLOIDAL SILICA}

Same as written above (accelerated migration) with exception of using nanoparticle solutions to the side of cathode. These solutions were Levasil CB8 (characteristics of Levasil CB 8 are shown in Table 2 and Sodium Methyl Siliconate (characteristics are shown in Table 3. 4

\subsection{NANO-SILICA}

Levasil CB8 colloidal solution was used in this experiment. Levasil CB8 is an alkaline, aqueous dispersion of colloidal silica that is approximately $50 \%$ solids by weight. The silica dispersion is sodium stabilized and the amorphous silica particles carry a negative surface charge. The $\mathrm{SiO}_{2}$ particles are discrete, have a smooth, spherical shape, and are present in a wide particle size distribution. The physical appearance of the dispersion is a white liquid, slightly more viscous than water. [5]

\subsection{Sodium Methyl Siliconate}

This solution is commonly used as hydrophobic protective layer of surfaces of natural stone, like sandstone, limestone etc. In our experiment the solution was diluted to $10 \%$ of solid contents.

\subsection{NATURAL CHLORIDE PENETRATION AFTER PROTECTION BY DISPERSION OF COLLOIDAL SILICA}

Samples prepared according to the procedure described under Protection by dispersion of colloidal silica were used for this experiment. The penetrated samples were then subjected to the procedure described in Natural chloride penetration. The side of the sample, which was exposed to colloidal silicon solution, was then exposed to a solution of $3 \% \mathrm{NaCl}$. Of course, samples were kept in constant laboratory temperature $\left(22 \pm 2{ }^{\circ} \mathrm{C}\right)$ for approximately 150 days. After that the samples were dried in heat chamber at $55^{\circ} \mathrm{C}$ for at least 7 days.

\subsection{Electro migration (ACCELERAted MIGRATION) AFTER PROTECTION BY DISPERSION OF COLLOIDAL SILICA}

Test started same way as Chloride electro migration. The surface of test sample, which was covered with a protective layer, was putted into this chamber with solution of $3 \% \mathrm{NaCl}$. Into the chamber on the other side of the sample was solution of $0.3 \mathrm{M} \mathrm{Na}(\mathrm{OH})$ added. Again, electrolytes were connected (to the anode side with 0.3 molar $\mathrm{NaOH}$ solution and to the cathode side with $3 \% \mathrm{NaCl}$ solution) to a power source with a constant voltage of $20 \mathrm{~V}$ for 48 hours. 4.

\subsection{DESCRIPTION OF CHLORIDE PROFILE MEASUREMENT}

On the prepared samples, the chloride profile and the amount of chlorides in the given concrete layer were measured. The chloride concentration was analysed in $5 \mathrm{~mm}$ depth-steps. It means, that the concrete specimens were drilled in $5 \mathrm{~mm}$ steps and the powder from drilling was collected in amount of $1.5 \mathrm{~g}$. The samples contained material from a depth of $0-5 \mathrm{~mm} ; 5-10 \mathrm{~mm} ; 10-15 \mathrm{~mm} ; 15-20 \mathrm{~mm}, 20-$ $25 \mathrm{~mm} ; 25-30 \mathrm{~mm} ; 30-35 \mathrm{~mm} ; 35-40 \mathrm{~mm} ; 40-45 \mathrm{~mm}$. The results show the values of "average" depth, i.e. $2.5 \mathrm{~mm} ; 7.5 \mathrm{~mm} ; 12.5 \mathrm{~mm} ; 17.5 \mathrm{~mm} ; 22.5 \mathrm{~mm}$; $27.5 \mathrm{~mm} ; 32.5 \mathrm{~mm} ; 37.5 \mathrm{~mm} ; 42.5 \mathrm{~mm}$. The scheme of the compared experiments is shown in Table 4. 44

Approximately $10 \mathrm{ml}$ of $20 \% \mathrm{HNO}_{3}$ was added to the collected $1.5 \mathrm{~g}$ powder samples and the sample was shaken carefully for approx. For 1 hour and then let to stabilize for approx. 24 hours. [4] 


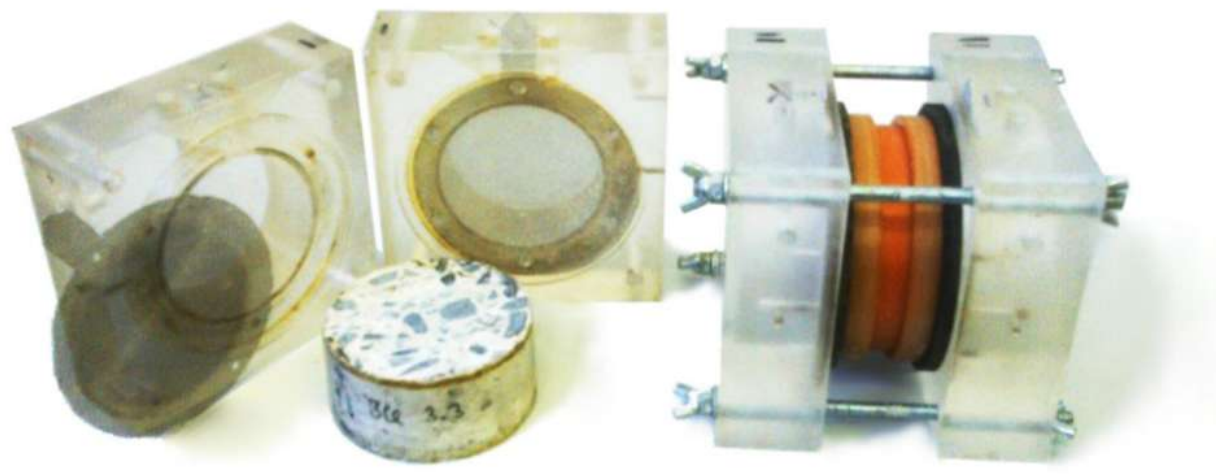

Figure 1. Electro migration chamber.

\begin{tabular}{ccc}
\hline \multirow{2}{*}{$\begin{array}{c}\text { Samples } \\
\text { NO2a }\end{array}$} & with NS protection & $\begin{array}{c}\text { natural penetration } \\
\text { accelerated migration }\end{array}$ \\
\cline { 2 - 3 } & with SMS protection & $\begin{array}{c}\text { natural penetration } \\
\text { accelerated migration }\end{array}$ \\
\cline { 2 - 3 } & with NS protection & $\begin{array}{c}\text { natural penetration } \\
\text { accelerated migration }\end{array}$ \\
\cline { 2 - 3 } LOmples & with SMS protection & $\begin{array}{c}\text { natural penetration } \\
\text { accelerated migration }\end{array}$ \\
\cline { 2 - 3 } & without protection & natural penetration \\
\hline
\end{tabular}

TABLE 4. Scheme of experiments.

Measurement of the concentration of chloride ions in the leaching solution was performed using the ion selective electrode and reference mercury sulphate electrodes SCANLAB SYSTEM. Prior to each measurement, the ion-selective electrode was calibrated in concentrated $\mathrm{KCl}$ solution. A total of 6 calibration solutions of 10-4 were prepared with concentration of $10^{-3} ; 3 \times 10^{-3} ; 10^{-2} ; 3 \times 10^{-2} ; 10^{-1}$. The calibration curve was set by breaking the values measured in the calibration solutions with a determination coefficient higher than 0.999. [4]

\section{Results AND Discussion}

All resulting values in all figures are the average values of the measurements made on 3 independent samples.

Figure 2 shows an electrical current waveform pattern in accelerated migration of chloride ion samples over a period of 48 hours. From the current flow in samples protected by dispersion of colloidal silica, it is obvious that the conductivity of the colloidal solution is lower, but also that the colloidal silicon particles in the solution have a truly negative charge. It is clear from this that the amount of chloride ion transferred was less with protection of Levasil CB8.

As above in figure 2 with the difference of used concrete. Figure 3 shows "Normal quality concrete". With this concrete the difference between used protective layer is extremely small.
Figure 4 shows the chloride profile in Normal quality samples after procedure of Natural chloride penetration. In comparison to unprotected samples, protection of Levasil CB8 shows zero level of protection, even the protected samples show higher concentrations of Chloride ions that unprotected ones. The real question is why $S M S$ protected samples shows this kind of graph and not the hyperbole as was expected.

Figure 5 shows the concentration of chloride ions in the samples of Low quality concrete. These samples were subjected to Protection of colloidal silica and Natural chloride penetration. All of those results the course of the chloride profile corresponds to the total periodic hyperbole that was expected for this type of test. Unlike the Figure 4 results we can say that the solution of SMS works to some degree. Absolute results show larger numbers that Normal quality concrete but that was quite the point of those mixtures.

Figure 6 shows the chloride profile in Normal quality samples with protective layer of colloidal silica. In comparison there are samples after natural diffusion and accelerated migration tests. Solution of Sodium Methyl Siliconate shows better results with protection.

In Figure 7 is shown the concentration of chloride ions in the samples of Low quality concrete. Samples subjected to Chloride electro migration show significantly lower chloride ion values than Naturally chloride penetration samples. The course of the Chloride electro migration profile in the Chloride electro migra- 


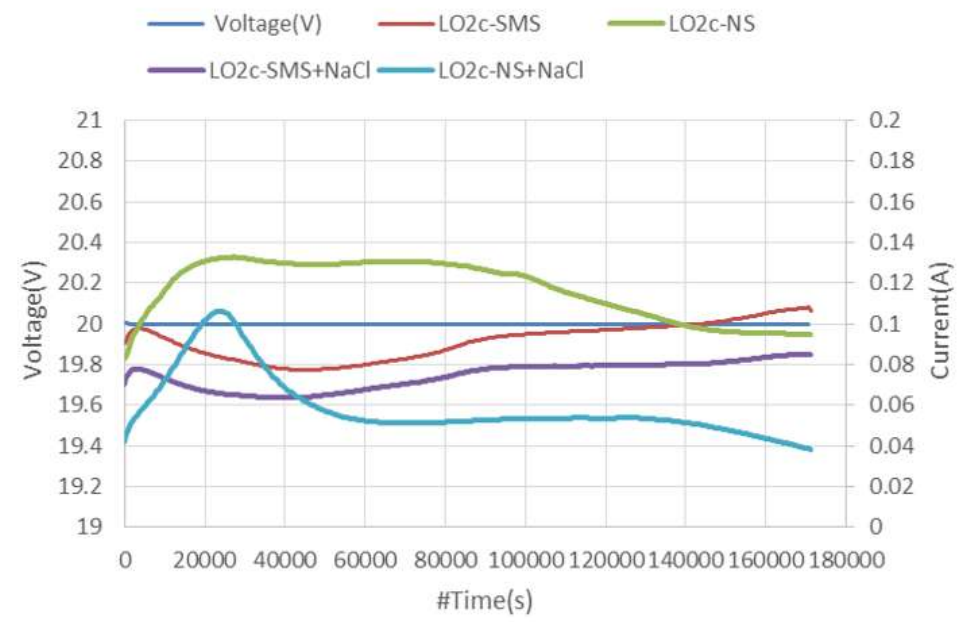

FIgURE 2. The course of the electrical current in the electrolyte during the preparation of the samples.

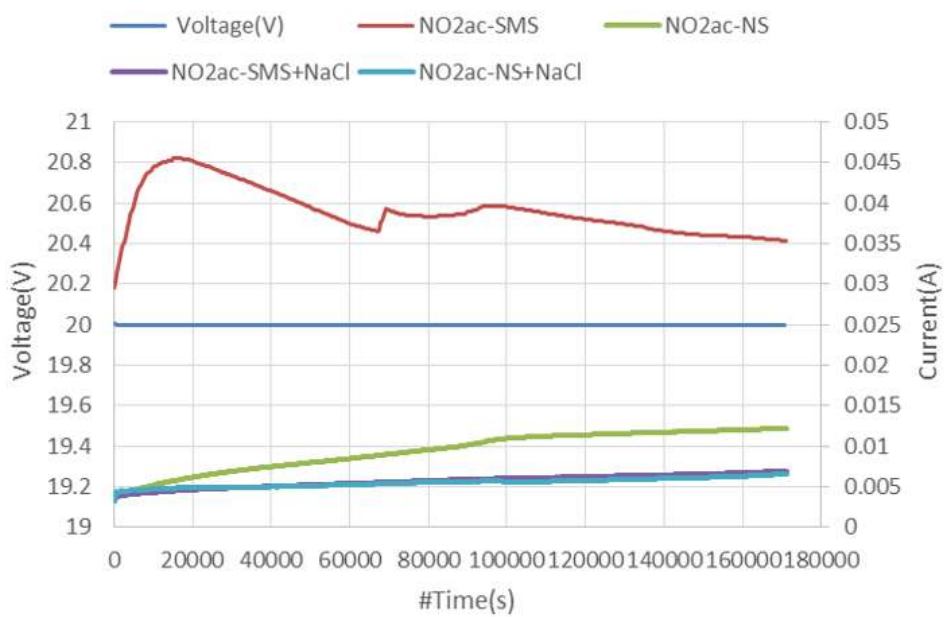

FigurE 3 . The course of the electrical current in the electrolyte during the preparation of the samples.

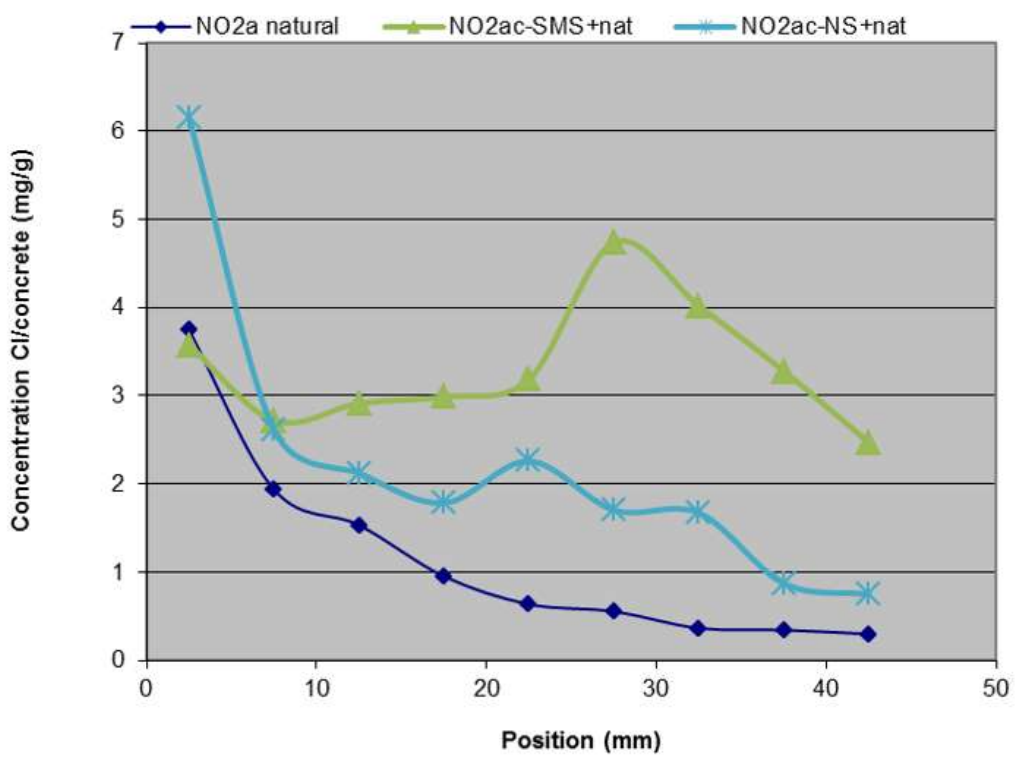

FIgURE 4. Concentration of chloride ions Normal quality concrete, Natural diffusion. 


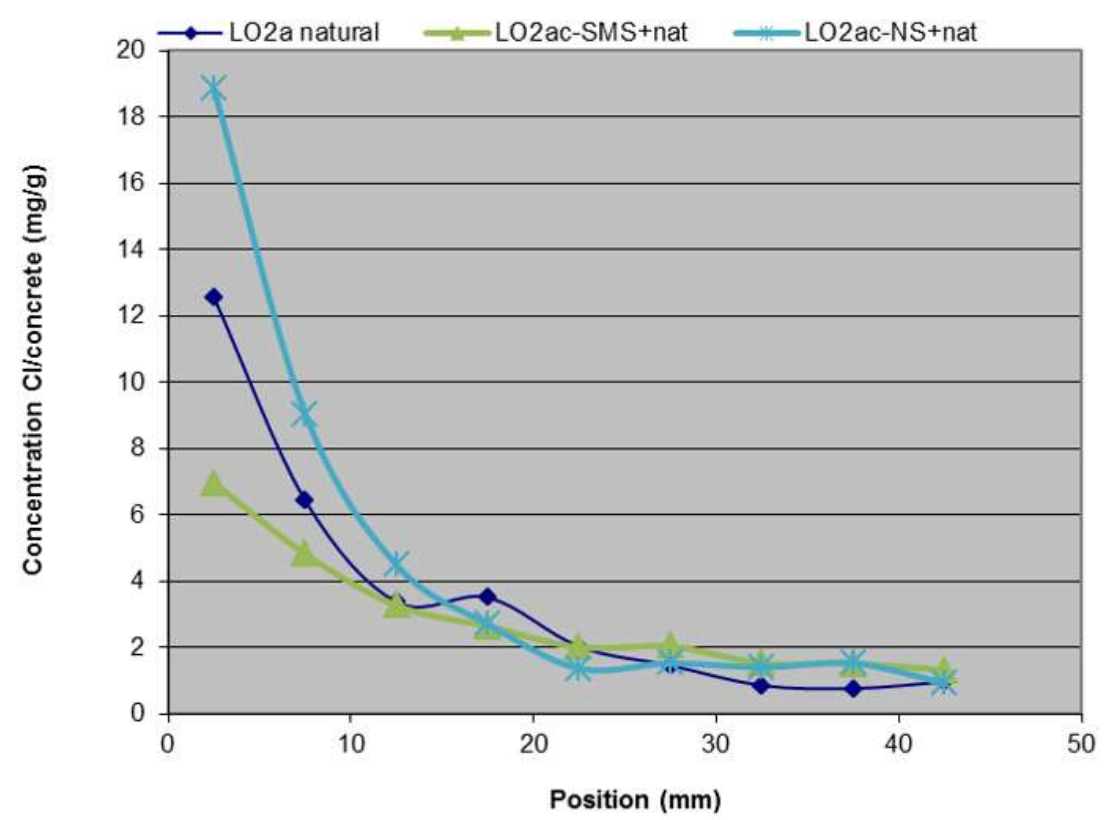

Figure 5. Concentration of chloride ions Low quality concrete, Natural diffusion.

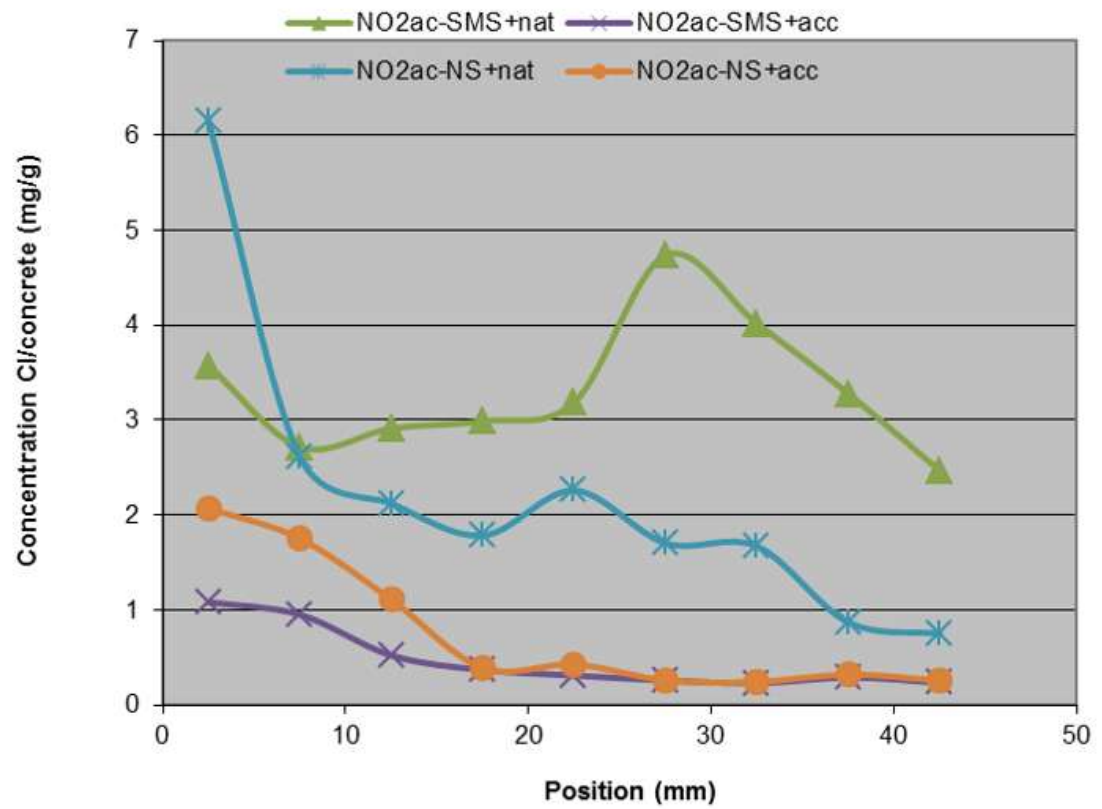

Figure 6. Concentration of chloride ions Normal quality concrete, Natural diffusion. 


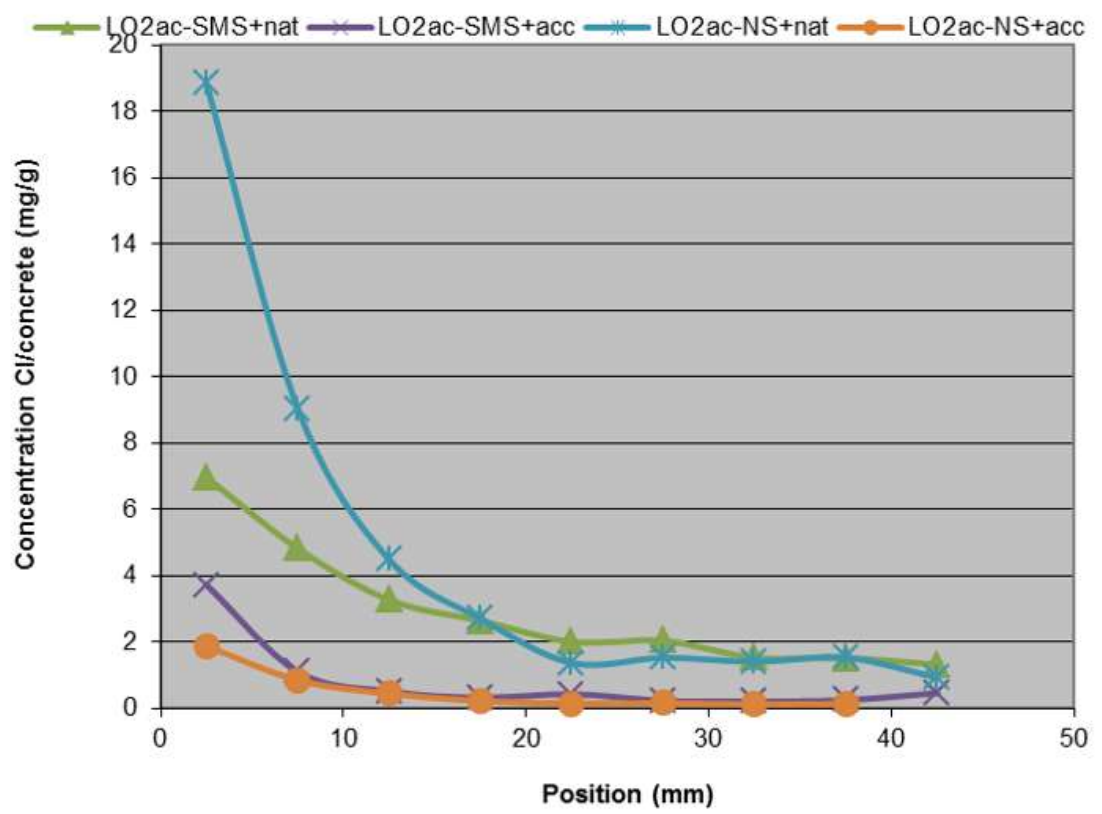

FiguRE 7. Concentration of chloride ions Low quality concrete, Natural diffusion.

tion sample suggests that only a very small amount of chloride ions were penetrated into the sample compared to Natural chloride penetration.

\section{SUmmary}

The results presented in this paper show the possibility of protection of concrete structures against the effect of chlorides dissolved in water. Many experiments have been carried out, which have demonstrated the possibility of simulating the acceleration of the chloride ion penetration into the concrete structure. Further experiments were performed showing the possibility of penetration of the concrete structure of micro particles. The results here are to be further checked on real-world constructions. The main points can be summarized as follows:

(1.) The chloride ion penetration into concrete can be simulated by passing the electric current through the electrolyte.

(2.) The simulated phenomenon is highly dependent on boundary conditions, in particular the strength of the electric current, effect of the time of the electric field and the concentration of the electrolyte solution.

(3.) The dispersion of colloidal silica can be penetrated by means of an electric current into concrete samples.

(4.) Dispersion of colloidal silica can have positive results when closing the porous concrete structure.
(5.) Dispersion of colloidal silica can reduce the amount of chloride ions dissolved in water when they penetrate into the concrete structure.

\section{ACKNOWLEDGEMENTS}

Financial support of the Czech Science Foundation (project 17-05360S) and the Grant Agency of the Czech Technical University in Prague (SGS16/135/OHK1/2T/11) is gratefully acknowledged.

\section{REFERENCES}

[1] R. Šulc, M. Himmel, J. Němeček. Chloride resistance of nanoparticle repaired concrete measured by accelerated tests. In Special Concrete and Composites 2017, vol. 760 of Key Engineering Materials, pp. 91-95. Trans Tech Publications, 2018. DOI:10.4028/www.scientific.net/KEM.760.91

[2] P. Hlaváček, J. Němeček. Accelerated chloride migration tests in concrete. In Engineering Mechanics 2016 - Book of full texts, pp. 1-4. Institute of Thermomechanics, AS CR, v.v.i., Prague, 2016.

[3] J. Němeček, P. Hlaváček, M. Kouřil, T. Jamborová. Electrochemical injection of nanoparticles into concrete. In Proceedings of the RILEM Conference. Materials, Systems and Structures in Civil Engineering 2016, Segment on Electrochemistry in Civil Engineering, pp. 81-87. Rilem Publications s.a.r.1., Prague, 2016.

[4] J. Němeček, Y. Xi. Nanotechnology in Construction, chap. Electrochemical injection of nanoparticles into existing reinforced concrete structures, pp. 213-218. Springer, New York, 2015.

[5] N. Akzonobel. LEVASIL CB8 colloidalsilica, Data Sheet. https://colloidalsilica.akzonobel.com/ construction/concrete/. 